\title{
A não univocidade do conceito de "autor" sob a perspectiva de Wittgenstein e Foucault
}

La no univocidad del concepto de autor desde la perspectiva de Wittgenstein y Foucault

The non-univocity of the concept of "author" from the perspective of Wittgenstein and Foucault

Eduardo Graziosi SiLVA, Daniel MARTINEZ-AVILA, Luciana de Souza Gracioso

Departamento de Ciência da Informação, Universidade Estadual Paulista, Av. Hygino Muzzi Filho, 737, Marilia, SP (Brasil) eduardograziosi@marilia.unesp.br, dmartinezavila@marilia.unesp.br, luciana@ufscar.br

\section{Resumen}

Debido especialmente a las Tecnologías de la Información y Comunicación (TIC), el concepto de "autor" y las formas de autoría se han ampliado independientemente del área en el que se crea el contenido. En este trabajo se analizan los usos, reutilizaciones y resignificados atribuidos al concepto de autor en los campos del Derecho, Ingeniería y Biblioteconomía bajo la perspectiva del "Juego de lenguaje" de Wittgenstein y el concepto de "autor" de Foucault. Se comprueba la no univocidad del concepto en función de las transformaciones en el tiempo y las reglas y convenciones de cada área de estudio.

Palabras clave: Autor. Autoría. Foucault, Michel. Wittgenstein, Ludwig.

\section{Introdução}

O conceito de "autor" não diz mais respeito apenas àquele que escreve textos, pinta quadros, compõe músicas ou canções, registra fotografias, mas também àquele que elabora pareceres e análises jurídicas, realiza pesquisas laboratoriais e de campo e provê o acesso à informação de forma equitativa e justa. Se antes era considerado "autor" a pessoa que produzia conteúdo para muitos, atualmente muitos podem produzir conteúdo para muitos, sobretudo devido à ubiquidade das Tecnologias de Informação e Comunicação (TICs). Desta forma, as possibilidades de autoria ampliam-se e, com ela, a própria definição do conceito de "autor". Surgem, assim, novos "autores", em distintas áreas, porém, nem sempre em plena concordância sobre o que torna um membro de uma determinada área "autor".

No momento de produção de um conteúdo, há entendimentos diversos sobre a função de "autor" entre as áreas do conhecimento. No Direito, por exemplo, a Lei de Direitos Autorais brasileira (Brasil, 1998) define "autor" apenas como pessoa física. A Ley de Propiedad Intelectual Española (España, 1996) define autor como pessoa "natural" e também abre a possibilidade de pessoas jurídicas. Na Biblioteconomia, o "autor" foi considerado, a partir do século XIX, no contexto da

\begin{abstract}
Due mainly to the Information and Communication Technologies (ICT), the concept of "author" and possibilities of authorship have been broadened, regardless of the area in which the content is created. From the perspective of Wittgenstein's "language games" and Foucault's concept of "author," we analyze the uses, reuses and resignifications attributed to the concept of "author" in the areas of Law, Engineering and, Library Science. We found a non-univocity of the concept based on its transformations and changes over time according to the rules and conventions of each area.
\end{abstract}

Keywords: Author. Authorship. Foucault, Michel. Wittgenstein, Ludwig.

elaboração de instrumentos bibliográficos, tanto como o responsável pela criação de bens intelectuais como uma entrada para a recuperação de documentos. Na Engenharia, por sua vez, a discussão desse conceito recai sobre diferentes aspectos, como o papel dos pesquisadores nas diversas fases de uma pesquisa e sobre a "contribuição essencial" que permite atribuir a um pesquisador a função de "autor".

A justificativa do estudo recai na medida em que demonstra como três áreas distintas do conhecimento, Direito, Engenharia e Biblioteconomia, articulam-se na definição de regras e como a participação de suas respectivas comunidades limita a função de "autor" internamente. Demonstra, ainda, como a organização própria de cada área delimita a definição do conceito de "autor", com destaque para suas práticas e os papéis desempenhados pelas comunidades discursivas. Por meio do apontamento de algumas de suas diferenças, sinaliza que não há um consenso universal sobre esse conceito, pois quando não há regras explícitas para defini-lo, práticas convencionadas entre os próprios membros cumprem essa função normalizadora.

Para compreender as condições que levam a construção de diferentes concepções sobre o conceito de "autor", serão utilizadas premissas 
da filosofia pragmática da linguagem, especificamente a defendida por Ludwig Wittgenstein (1889-1953) em seu segundo momento filosófico caracterizado pela produção de sua obra Investigações filosóficas (1953), apropriando-se especificamente da expressão cunhada pelo filósofo de "jogos de linguagem" de Wittgenstein (2009), que prerroga que o uso e o significado das palavras são dinamicamente construídos, reconstruídos e ressignificados pela própria comunidade usuária. Utilizar-se-á, ainda, o estudo de Foucault (1984) sobre o conceito de "autor", mostrando que esse não possui uma definição única, haja vista que os conceitos estão expostos a diferentes comunidades, cada qual com seu discurso, em espaços e tempos distintos.

A seleção da área do Direito deve-se ao fato do tema Direito Autoral ser de interesse de pesquisa dos autores, bem como devido às discussões acerca da autoria na esfera digital; a Engenharia, por ser uma das áreas em que a questão da autoria é bastante debatida, ao lado da Computação onde, como consequência de sua complexidade, surgiu o movimento de software livre fundado por Richard Stallman, que revolucionou a concepção legal de autoria por meio do Copyleft; e a Biblioteconomia, por ser a área de formação dos autores e também para ampliar o entendimento sobre o conceito de "autor", especificamente no contexto da Produção e Organização do Conhecimento.

\section{Breve introdução a Wittgenstein e Foucault}

As potenciais definições de conceitos dão-se entre os membros de uma comunidade, assim como seus significados e a formulação de suas regras de uso. Tal argumento foi demonstrado por Ludwig Wittgenstein, filósofo austríaco, em um momento de sua carreira que ficou conhecido como "a segunda virada linguística".

Em um primeiro momento, Wittgenstein, durante seus estudos de Engenharia Mecânica, tomou contato com as obras de Gottlob Frege (18481925) e Bertrand Russell (1872-1970), despertando seu interesse em Lógica e, assim, seguindo os pressupostos desses estudiosos em busca de uma linguagem ideal. Esse período foi marcado pela obra intitulada "Tratado lógico-filosófico", publicada em 1921, onde explica a natureza factual e representativa da linguagem, consoante à predominante filosofia analítica, que propunha tornar a linguagem uma forma de pensamento calculável para tornar o filosofar uma construção lógica.

No entanto, ao longo do tempo Wittgenstein reconheceu que uma linguagem ideal não poderia ser plenamente utilizada em todas as áreas, o que o levou a mudar de uma concepção lógica para uma concepção pragmática da linguagem. Em seu segundo momento filosófico, passou a entender que a forma como as palavras eram utilizadas e suas regras de uso eram definidas no momento e no contexto de seu uso. Isto o levou a formular o conceito de "jogos de linguagem", cunhado na obra "Investigações filosóficas" (1953), que marca o reposicionamento de seu pensamento.

"Jogos de linguagem" (Sprachspiel), segundo o próprio Wittgenstein (2009, p. 19), é "a totalidade formada pela linguagem e pelas atividades com as quais ela vem entrelaçada". Saldanha e Gracioso (2014) esclarecem que cada termo possui múltiplos usos e sua aplicabilidade não necessita de elementos em comum, mas seus significados estariam relacionados por semelhanças. Portanto, esse conceito é útil para compreender os usos e as oscilações naturais da significação das palavras em comunidades e contextos específicos, além de permitir compreender as regras de formulação e uso estabelecidas.

Isso posto, destaca-se que o conceito de "autor" foi estudado por Foucault (1984) principalmente, em sua obra "O que é um autor". O filósofo francês, nascido em 1926, cresceu em um ambiente conservador e estudou na Escola Normal Superior de Paris com os filósofos Jean Hypolitte e Louis Althusser. Em 1948, incentivado por Althusser, ingressou no Partido Comunista, desligando-se em 1953 devido à repressão à homossexualidade e ao antissemitismo. Foucault transitou, principalmente, pela Filosofia e Psicologia, apresentando seus estudos em várias obras, dentre elas, "Doença mental e personalidade" ("Maladie mentale et personnalité", 1954), "Loucura e civilização" ("Folie et Déraison: Histoire de la folie à l'âge classique", 1961), "O nascimento da clínica" ("Naissance de la clinique: une archéologie du regard médical", 1963), "As palavras e as coisas" ("Les mots et les choses: Une archéologie des sciences humaines", 1966), "A arqueologia do saber" ("L'Archéologie du savoir", 1969) e "O que é um autor" ("Qu'est-ce qu'un auteur?", 1969). Esta última trata-se, na realidade, de um ensaio em resposta ao texto de Roland Barthes "A morte do autor" ("La mort de l'auteur", 1968), no qual declara que o autor não cria mais textos a partir de sua imaginação, mas sempre são gerados a partir de textos e ideias preexistentes. Foucault, por sua vez, atribui ao autor uma função discursiva, preocupando-se com a circulação do discurso, além de entendê-lo como uma entidade psicológica e como um termo para designar o conjunto de uma obra.

Diante desta breve introdução às teorias de Wittgenstein e Foucault, em especial a partir da compreensão da significação da expressão "jogos de linguagem", objetiva-se compreender a 
definição de "autor" nas áreas de Direito, Engenharia e Biblioteconomia, conforme mencionadas anteriormente. Para tanto, foram elencados exemplos na literatura que trazem definições e regras sobre o conceito de "autor" a fim de compreender, em cada área, o entendimento sobre o mesmo e como seus membros foram nomeados como "autores". Posteriormente, o estudo de Foucault (1984) sobre o autor é apresentado para explicar a não univocidade acerca desse conceito. Para melhor compreendê-lo, apresenta-se um breve histórico do Direito Autoral e, em seguida, o entendimento do Direito sobre o mesmo.

\section{Origens do Direito Autoral e do conceito de "autor" no Direito}

Na Antiguidade Clássica, não havia o reconhecimento dos direitos autorais básicos, que só seriam reconhecidos com a invenção da tipografia e da imprensa. Efetivamente, esses direitos passaram a ser resguardados a partir da promulgação do Copyright Act, em 1710, pela rainha Ana da Inglaterra, visando à exploração econômica das obras e contribuindo para a criação de legislações nacionais nos demais países (Carboni, 2010). Posteriormente, durante o lluminismo francês, foi criado o modelo droit d'auteur, que além da exploração econômica, inovou ao acrescentar o direito moral do autor. A legislação brasileira, consoante o modelo francês, prevê os direitos morais do autor, isto é, o direito de personalidade, e o direito patrimonial, que permite explorar economicamente os bens imateriais. A lei autoral atualmente em vigor no Brasil é a 9.610/98, que altera, atualiza e consolida a legislação sobre direitos autorais e dá outras providências (Brasil, 1998).

$\mathrm{Na}$ legislação brasileira, "autor" é definido como "a pessoa física criadora de obra literária, artística ou científica" (Brasil, 1998). Na legislação espanhola é definido como "la persona natural que crea alguna obra literaria, artística o científica" (España, 1996). Na Lei espanhola também se indica que:

Se presumirá autor, salvo prueba en contrario, a quien aparezca como tal en la obra, mediante su nombre, firma o signo que lo identifique. [...] Cuando la obra se divulgue en forma anónima o bajo seudónimo o signo, el ejercicio de los derechos de propiedad intelectual corresponderá a la persona natural o jurídica que la saque a la luz con el consentimiento del autor, mientras éste no revele su identidad.

Considerando-se suas datas de promulgação originais, observa-se que as mesmas foram criadas em um contexto no qual as TICs ainda eram incipientes e, por isso, havia pouca possibilidade de criação de conteúdo digitais. Na atualidade, porém, aquelas tecnologias possibilitaram às pessoas tornarem-se autoras de conteúdos diversos.
Dentre as "autorias" surgidas neste contexto, Carboni (2010) aponta a meta-autoria em obras criadas por sistemas computacionais e a pluriautoria nas criações colaborativas. No primeiro caso, temse como exemplo a criação do programa de computador AARON pelo pintor abstracionista Harold Cohen em 1968, por meio do qual o usuário apenas definia o tempo de duração da obra, enquanto que o programa, por meio de uma mão protética, cria as obras espontaneamente a partir dos padrões de imagens de seu criador. A pluriautoria, por sua vez, é exemplificada com o software livre, que é criado por pessoas do mundo todo e distribuído livremente de forma que qualquer usuário possa acessar seu código fonte e aperfeiçoá-lo.

Ressalta-se, ainda, que embora a lei considere apenas pessoa física como autor, o parágrafo único do artigo 11 da Lei Brasileira discorre que "A proteção concedida ao autor poderá aplicarse às pessoas jurídicas nos casos previstos nesta Lei" (Brasil, 1998) e na Lei Espanhola, analogamente, "de la protección que esta Ley concede al autor se podrán beneficiar personas jurídicas en los casos expresamente previstos en ella" (España, 1996). Por se tratar de fruto de criação de pessoa física, os direitos relativos aos bens intelectuais podem ser cedidos para pessoas jurídicas, que se tornam titulares dos direitos autorais, conforme a extensão da cessão. No que se refere à Administração Pública Brasileira, ela pode se tornar detentora desses direitos em atividades de fomento à cultura, na contratação de obras intelectuais e na produção de obras intelectuais por meio de seus servidores (Escola Nacional de Administração Pública, 2015a).

Além disso, a lei prevê a existência de coautoria, ou seja, obras que foram criadas conjuntamente por dois ou mais autores. Conforme o conteúdo, as obras em coautoria classificam-se em divisíveis, como uma coletânea de contos ou poemas com textos de dois ou mais autores, e indivisíveis, por exemplo, um livro, no qual não é possível identificar, efetivamente, a contribuição de cada autor. A lei brasileira ressalta, ainda, que o auxílio prestado aos autores na revisão, atualização, fiscalização ou edição não configura coautoria, remetendo à questão da "contribuição efetiva" para a criação de uma obra intelectual, que será discutida posteriormente (Escola Nacional De Administração Pública, 2015b). Na Lei espanhola (España, 1996), a coautoria é regulada no "Artículo 8. Obra colectiva" do Título II "Sujeto, objeto y contenido", Capítulo I "Sujetos", que diz:

Se considera obra colectiva la creada por la iniciativa y bajo la coordinación de una persona natural o jurídica que la edita y divulga bajo su nombre y está constituida por la reunión de aportaciones de diferentes autores cuya contribución personal se funde en 
una creación única y autónoma, para la cual haya sido concebida sin que sea posible atribuir separadamente a cualquiera de ellos un derecho sobre el conjunto de la obra realizada. Salvo pacto en contrario, los derechos sobre la obra colectiva corresponderán a la persona que la edite y divulgue bajo su nombre.

Assim, na visão do Direito, depreende-se que o conceito de "autor" é regido pela definição da lei. Embora não contemple pessoa jurídica como "autor", sua proteção está legalmente prevista. Da mesma forma, a menção à coautoria contempla outra modalidade de criação de obras intelectuais. Os limites legais impostos pelas definições visam uniformizar o entendimento sobre o conceito de "autor" para que a comunidade jurídica participe do mesmo "jogo de linguagem", conforme prevê Wittgenstein (2009), porém, como anteriormente comentado, o conceito encontra-se defasado frente ao contexto tecnológico atual, pois não contempla as diversas formas de autoria possibilitadas pelas TICs, como a meta-autoria e pluriautoria.

\section{O conceito de "autor" na Engenharia}

Permeada pela realização de pesquisas, a Engenharia, enquanto área do conhecimento, visa contribuir para a melhoria da qualidade de vida da sociedade por meio do emprego de técnicas que criem soluções para o bem-estar social. Inúmeros são os atores envolvidos e os papéis por eles desempenhados no decorrer de uma pesquisa, o que faz que com o conceito de "autor" torne-se relativamente difuso nessa área, isto é, não há regras explícitas de autoria, mas convenções tacitamente definidas pelos pesquisadores.

A questão da autoria, fortemente relacionada à ética, por vezes é controversa na Engenharia, seja pelo fato dessa área do conhecimento estar cada vez mais desenvolvendo pesquisas conjuntas com outras áreas, portanto, defrontando-se com interesses diversos, seja pelo fato de haver certo ceticismo entre a indústria e os pesquisadores, quando realizam projetos conjuntos (Borenstein, 2011). Em ambas as situações, há limites e entendimentos nebulosos que, somados aos diferentes interesses, implicam em interpretações distintas sobre aspectos relacionados à ética, assim como em relação ao conceito de "autor".

No que se refere à ética, as interpretações podem recair sobre o desenvolvimento de uma determinada tecnologia ou sobre a melhoria de um processo ou produto existente, que podem culminar em uma patente ou em um modelo de utilidade, por exemplo. Para tanto, os autores devem discriminar precisamente nesses documentos suas criações para justificar a concessão da ex- ploração respeitando, assim, a propriedade intelectual alheia. Em relação à autoria, Borenstein (2011) comenta que há uma carência de padronização sobre a determinação da ordem dos autores nas publicações de Engenharia. Nos diversos campos há maneiras diferentes de padronização: enquanto algumas publicações indicam como último autor o diretor de um laboratório como o pesquisador sênior, outras indicam o estudante de pós-graduação como o primeiro. Além disso, nem sempre a indicação da ordem de autoria corresponde ao grau de contribuição dos autores, como é o caso de uma ordenação alfabética, pois esta é apenas mais uma convenção utilizada na Engenharia.

A existência de diferentes convenções não é prejudicial, haja vista que reconhecidas publicações científicas e laboratórios devem ter liberdade para definir suas próprias regras, mas também devido essa diferença torna-se difícil relacionar o nível de contribuição dos autores (Borenstein, 2011). O importante é que haja um entendimento comum sobre o significado do conceito e sua aplicabilidade entre seus membros, a fim de que não haja distorções no próprio discurso da comunidade que o utiliza, em consonância com a definição de "jogos de linguagem" de Wittgenstein (2009).

Entre as diferentes orientações para autores nas publicações de Engenharia, há um ponto comum que diz respeito à "contribuição significativa" realizada pelos participantes de uma pesquisa, ainda que não haja concordância na sua definição. Borenstein (2011) também discute se é honesto incluir os indivíduos que coletaram dados e os lançaram em bases de dados como "autores", isto é, se o desempenho dessas funções permite serem considerados como tais.

Além das questões apontadas, tem sido cada vez mais comum a realização de intercâmbios por estudantes e a consequente realização de pesquisas conjuntas. Embora haja um entendimento internacional comum sobre ética na pesquisa, podem haver diferenças de interpretação entre os países e, consequentemente, interesses diversos sobre questões como plágio e reuso de dados de pesquisa. Por isso, é importante que os estudantes observem as regras do periódico do país no qual irão publicar. Além disso, há também a questão da edição de manuscritos por falantes não-nativos, o que pode ocasionar modificações gramaticais, por exemplo, e como há um pressuposto de que os "autores" são aqueles que contribuíram significativamente para o trabalho, o "editor de língua" poderia ser listado na seção de agradecimentos do mesmo, posto que se configura como contribuição intelectual de importância diferenciada (Borenstein, 2011). 
Em resumo, percebe-se que a conceito de "autor" na Engenharia por vezes segue regras explícitas, como aquelas nas instruções de publicações da área, e por vezes implícitas, como convenções estabelecidas entre os próprios sujeitos que desenvolveram uma pesquisa. Destaca-se, ainda, a preocupação em se definir um "autor" a partir de sua "contribuição significativa", isto é, se o papel desempenhado durante a realização de uma pesquisa pode tornar um sujeito "autor". Por fim, a definição do conceito também recai sobre a realização de intercâmbios e o consequente estabelecimento de parcerias internacionais de publicação e, dessa forma, deve-se atentar para as normas do periódico observando-se o país em que é editado.

\section{O conceito de "autor" na Biblioteconomia}

Smiraglia, Lee e Olson (2011) concentraram-se em entender o papel da autoria em instrumentos bibliográficos, voltando-se, mas não exclusivamente, para as regras de catalogação. Na Grécia antiga, os autores discorrem sobre os Pinakes redigidos por Calímaco, os quais arrolavam oradores, poetas, filósofos e outro autores e suas obras, enquanto que na China antiga, a preocupação com a autoria é exemplificada com os Sete Epítomes, catálogo criado a partir dos Separate Résumés, uma coleção de registros bibliográficos anotados e que distinguia três tipos de autoria: compositor, transmissor (na forma oral ou escrita) e editor/compilador, funções que se confundiam quanto mais antiga fosse a obra. A análise feita por Smiraglia, Lee e Olson (2011) sugere certa similaridade com a concepção ocidental, isto é, "autor" é aquele que fala ou escreve com autoridade. Além disso, Smiraglia e Lee (2012) comentam que, embora os Sete Epítomes relacionem autores e obras, essa relação não se estende para um princípio organizador, pois autor e título não funcionavam como entradas para recuperar os documentos, mas eram localizados por meio de um sistema de classificação de valores morais dos autores. Por isso, nem sempre as obras eram reunidas na mesma classe, visto que os valores morais determinavam sua classificação.

Posteriormente, a tradição anglo-americana passou a considerar não o aspecto biográfico, mas sim técnico do "autor". Com a publicação das 91 regras de catalogação para o Museu Britânico em 1841, Panizzi determina que o catálogo seja organizado por ordem alfabética de autor, demonstrando preocupação com o nome e sua respectiva forma (Smiraglia et al., 2011). Foi Panizzi quem também forneceu as primeiras entradas úteis: além do título, considerava informações de edições, editores, traduções e conteúdo intelectual (Smiraglia e Lee, 2012). Já em finais do mesmo século, Cutter também se preocupava com o nome e sua forma, mas definia o "autor" em um sentido estrito, como aquele que escreve um livro, e em um sentido amplo, como aquele que organiza textos de vários autores. Em meados do século XX, Charles Coffin Jewett apresenta uma nova abordagem sobre a autoria na obra "On the construction of catalogues of libraries, and their publication by means of separate stereotyped titles: with rules and examples", publicada em 1953, pois estende o princípio de autoria e entidades corporativas sob seus nomes, corroendo ainda mais a caracterização pessoal do nome do autor. Verifica-se, assim, que nessa tradição, o nome do autor assume uma grande responsabilidade no catálogo, embora não como uma ligação entre o nome próprio e a pessoa que descreve, porém mais como um elemento de designação de uma classificação alfabética de obras. Mais recentemente, o código de catalogação RDA traz uma mudança terminológica do conceito de "autor" em relação ao AACR2, pois propõe o termo "criador" para englobar amplamente pessoas e instituições responsáveis pela concepção de bens intelectuais, enquanto que "autor" fica restrito àquele que cria, principalmente, bens textuais (Smiraglia et al., 2011).

Diante do exposto, vê-se que o conceito de "autor" na Biblioteconomia, especialmente na construção de catálogos, sofreu modificações ao longo do tempo em função das concepções de autoria adotadas pelas diferentes sociedades. $\mathrm{Na}$ Grécia Antiga, os autores e suas respectivas obras eram arrolados nos Pinakes, assim como na China Antiga, que ainda utilizava uma classificação baseada nos valores morais, dificultando, relativamente, o agrupamento das obras, mas sem deixar de relacioná-las com o respectivo autor. Já no século XIX, Panizzi e Cutter preocuparam-se com o autor (e outras funções intelectuais) enquanto entrada no catálogo, visando à recuperação dos documentos, ao passo que Jewett estendeu o princípio de autoria e entidades corporativas sob seus nomes no século seguinte e, mais recentemente, o RDA introduziu o conceito de "criador", distinguindo-o da definição de "autor" adotada pelo AACR2.

Desta forma, compartilha-se a reflexão de Smiraglia e Lee (2012) de que a atribuição é uma forma de classificação cultural por meio da qual o nome de um "autor" torna-se o nome de uma classe de discurso. Portanto, "autor" não representa mais criadores únicos, nem um princípio organizador como entrada para recuperação de documentos, mas estabelece uma associação como identificador de trabalhos relacionados. Por exemplo, o 
programa de televisão "The French Chef", apresentado por Julia Child, deu origem a obras derivadas que tiveram a participação intelectual de várias pessoas, assim, para representá-lo por meio de um sistema culturalmente orientado por meio de identificadores, Smiraglia e Lee (2012) defendem a adoção de "The French Chef" como entrada de um catálogo ao invés de Julia Child, propondo uma revisão do conceito de autoria enquanto princípio ordenador do catálogo. Finalmante, no trabalho de Martínez-Ávila, Smiraglia, Lee e Fox (2015) realizou-se uma análise do discurso foucaultiano dos já citados "Sete Epítomes", as "Obras de Abelardo" (discutida por Panizzi), e o caso moderno do "The French Chef ", de Julia Child, em ferramentas atuais da web concluindo que a atribuição do autor nos catálogos não concorda com a concepção discursiva de Foucault sobre "autor".

Para melhor compreender as diferenças identificadas sobre o conceito de "autor", a próxima seção apresenta os estudos de Foucault (1984) sobre o tema e o tratamento conferido a esse conceito.

\section{Foucault e o conceito de "autor"}

Olsson (2010) indicava que Foucault era pouco explorado na Biblioteconomia pelo fato da área ter se concentrado no comportamento de busca e nos processos mentais do indivíduo. Na pesquisa e na prática profissional, houve influência do modelo de transferência de informação, segundo o qual os textos eram recebidos pelos leitores passivamente, ao passo que a análise do discurso foucaultiana esclarece que o processo é justamente o inverso: os leitores participam na construção do significado, juntamente com o texto e o contexto social em que estão inseridos. Especialmente na última década, diversos autores e trabalhos aplicaram o trabalho de Foucault e a análise de discurso na Biblioteconomia e na Organização do Conhecimento (Frohmann, 1992, 1994a, 1994b, 2001; Budd e Raber 1996; Budd, 2006; Martínez-Ávila, 2012; Moulaison et al., 2014; Martínez-Ávila e Fox, 2015; Moraes et al., 2016; Castanha et al., 2017; Silva et al., 2017).

Da mesma forma que propõe uma releitura do processo de significação de um texto, Foucault faz o mesmo com o conceito de "autor", para o qual propõe uma reformulação da relação entre autor, texto e leitor. Em seu artigo "O que é um autor", o filósofo reduz o "autor" para uma função no discurso, descrevendo-o como "uma categoria ou forma de organização de textos que tem uma história e necessidades para serem desafiadas" (O'Farrell, 2007, tradução nossa), esclarecendo que a entidade física "autor" e "autor" enquanto organização de textos devem ser tratadas separadamente. Ao discorrer sobre esse conceito, Foucault (1984) considera que as "obras" de um "autor" não se limitam a textos, mas a todo tipo de discurso gerado por ele, sejam rascunhos, obras inacabadas e outros textos.

Diante disso, o filósofo identifica quatro características acerca do "autor". Os discursos por ele produzidos são objetos de apropriação, cujo surgimento é posterior à atual apropriação penal, pois as obras passaram a ter autores (exceto figuras míticas e sacralizadas) a partir do momento em que seus discursos poderiam ser transgressores. A segunda explica que a função de "autor" não afeta todos os discursos de forma universal e constante: as obras literárias, por exemplo, eram aceitas sem contestação ou atribuição exata de autoria, ao passo que a partir da Idade Média, época em que se inicia o surgimento de obras científicas, o valor de verdade aparece quando o "autor" é explicitamente citado para validar seu discurso como uma declaração verdadeira. A terceira característica expõe que a função de "autor" não se desenvolve espontaneamente como a atribuição de um discurso a um indivíduo, mas é "resultado de operações complexas que constroem uma certa racionalidade que chamamos 'autor"' (Foucault, 1984, p. 10, tradução nossa). A última, por sua vez, discute que o "autor" é uma fonte de expressão que procura tanto explicar a presença de determinados eventos em suas obras, mas também transformações, distorções e modificações sofridas, além de neutralizar contradições que podem surgir nas mesmas, a fim de organizálas em torno de uma contradição fundamental ou de origem (Foucault, 1984).

Por meio dessas características, constata-se que o poder de um "autor" se estende para além da criação de bens intelectuais: seu nome não é apenas um elemento no discurso, mas "executa um papel no que se refere ao discurso narrativo, assegurando uma função classificatória" (Foucault, 1984, p. 107, tradução nossa) e possibilita reunir, diferenciar, contrastar e estabelecer relações entre obras.

Como Foucault considera como "obra" toda a produção de um "autor", isto é, rascunhos, esboços e outros textos, geralmente por estarem dispersas no tempo e no espaço, seu agrupamento com o respectivo "autor" é dificultado, assim como a identificação da responsabilidade intelectual. Diante dessa "ausência autoral", por vezes motivada por dificuldades inerentes à complexidade da produção intelectual de um conjunto de obras, por outras motivadas pelos interesses próprios das áreas do conhecimento estudadas, o que se percebe ao longo do tempo, mais do que um esforço para resguardar os bens intelectuais gerados pela sociedade, é atribuir às obras, da 
melhor forma possível e a partir das possibilidades de cada época, a autoria que lhe é devida.

\section{Considerações sobre o conceito de "autor" identificado nas três áreas}

A partir da compreensão das concepções de "autor" nas três áreas analisadas (Direito, Engenharia e Biblioteconomia), constata-se o estabelecimento de diferentes "jogos de linguagem" para a construção do significado do conceito, assim como a definição de regras de uso e aplicação próprias de cada uma. No Direito, inicialmente os editores foram protegidos pelo Copyright Act, prevalecendo os direitos patrimoniais, e posteriormente o lluminismo acrescentou os direitos morais. Atualmente, o conceito é influenciado pelas TICs e inclui a pessoa jurídica, guardadas as devidas proporções, como "autora". Por isso, entende-se como natural as modificações acerca do conceito de "autor", haja vista que as mudanças sociais implicam em mudanças legais. Na Engenharia, por sua vez, o conceito de autor não possui a mesma normalização que no Direito, pois constatou-se que essa área se preocupa predominantemente com a técnica, o que leva os pesquisadores a transitarem da autoria de produtos $\mathrm{e}$ processos à autoria acadêmica, quando da comunicação dos resultados alcançados. Embora sociedades científicas e periódicos acadêmicos de Engenharia publiquem manuais e regras para guiar os autores no processo de escrita, a definição de "autor" nem sempre segue regras explícitas, seja porque não constam naqueles documentos, seja porque ficam sujeitas ao consenso entre os pesquisadores que desenvolveram o trabalho, por exemplo, o nível de participação na pesquisa ou o cargo que o pesquisador ocupa em um laboratório. Na Biblioteconomia, constatam-se diferentes concepções de "autor" nas sociedades grega e chinesa antigas, que se preocupavam em arrolar autores e obras e listá-los, também, segundo os valores morais, respectivamente; no século XIX, com Panizzi e Cutter, que retiraram o caráter biográfico e atribuíram um caráter técnico ao "autor", enquanto entrada para recuperação de documentos; e no século XX, com Jewett aplicando o princípio da autoria a entidades corporativas, sendo a concepção mais recente aquela apresentada pelo RDA, que expõe o conceito de "criador", reservando ao "autor" a responsabilidade pela criação de conteúdos textuais.

Guardadas as devidas diferenças entre as áreas, percebe-se que o conceito de "jogos de linguagem" de Wittgenstein (2009) contribuiu para esclarecer que, de fato, cada comunidade utiliza a linguagem para os fins que atendam suas necessidades, e além disso, nota-se que ela serviu aos seus interesses em tempos específicos, como exemplificado no Direito e na Biblioteconomia. Desta forma, verifica-se a existência de não univocidade do conceito de "autor", tanto dentro de uma mesma área como em diferentes momentos de sua evolução.

\section{Conclusões}

A partir da noção de "jogos de linguagem" de Wittgenstein (2009) evidenciou-se que as regras e acordos estabelecidos pelas áreas visaram o entendimento acerca do conceito de "autor" para atender seus respectivos interesses, mas o que se verifica é que, durante o desenvolvimento de cada uma, o próprio conceito sofreu alterações para atender aos presentes e futuros interesses que surgiriam. Por isso, a partir de Foucault (1984) constata-se que não há univocidade no conceito de "autor", pois segundo o filósofo não podem ser definidas categorias universais para a definição de conceitos e, portanto, não possuem essência: tratam-se de noções restritivas, isto é, atendem a interesses específicos de um espaço e tempo definidos.

Ressalta-se, entretanto, que essa não univocidade é decorrente das diferenças internas de cada área acerca da formulação do significado do conceito. Isso posto, o que se verificou no Direito foi um entendimento do "autor" pessoa física ou "natural", com proteção à pessoa jurídica dentro dos limites legais possíveis, além da influência das TICs no que se refere ao surgimento da meta-autoria e pluriautoria. Na Engenharia, constataram-se entendimentos implícitos sobre a autoria a partir de "contribuições significativas" dos pesquisadores e também das funções que exercem no desenvolvimento de pesquisas. Na Biblioteconomia, por fim, a consolidação do conceito de "autor" passou de um caráter biográfico e subjetivo para um caráter técnico, sendo que desde então serviu como entrada nos catálogos para a recuperação da informação.

Se por um lado as diferenças existentes entre o conceito apontam para concepções particulares da produção de bens intelectuais, por outro apresentam uma preocupação comum, qual seja, a atribuição de crédito aos responsáveis por tais bens. Embora Foucault (1984) demonstre pouca preocupação com quem fala, posto que em sua visão o "autor" é uma função discursiva, há que se considerar que se alguém fala, é por meio de alguma obra, independentemente de sua forma de expressão.

Assim, não se pode falar em "autor" se não se falar em "obra". As diversas formas de relação entre esses dois elementos propostas pelas áreas estudadas foram bem-sucedidas em suas 
respectivas épocas, atendendo às regras dos "jogos de linguagem" dos grupos que as formularam. Os autores de cada momento histórico serviram e continuam servindo aos propósitos de suas áreas do conhecimento, por mais que os critérios para defini-los tenham sofrido modificações ao longo do tempo, ora sendo chamados de editores, ora de compiladores, dentre outras funções intelectuais possíveis. No contexto atual, fortemente influenciado pelas TICs, há que se estar preparado para o surgimento de funções intelectuais vindouras e produtoras de discursos ainda desconhecidos. De fato, Foucault (1984) talvez estivesse à frente do seu tempo ao atribuir ao autor uma função discursiva, preocupando-se com a circulação de seu discurso, à apropriação pelas pessoas e com os lugares em que circula, pois pela forma e velocidade com que são produzidos atualmente, o discurso pode vir a se sobrepor ao autor, deixando-o em plano inferior e, realmente, pouco importando quem fala, mas o que, onde, para quem e como se fala.

\section{Referências}

Borenstein, Jason (2011). Responsible authorship in engineering fields: an overview of current ethical challenges. // Science and Engineering Ethics. 17 (2011) 355-364.

Brasil (1988). Lei no 9.610/98, de 19 de fevereiro de 1998. Diário Oficial [da] República Federativa do Brasil, Brasília, DF, 20 fev. 1998. http://www.planalto.gov.br/CClVIL_03/leis/L9610.htm (07-09-2015).

Budd, John (2006). Discourse analysis and the study of communication in LIS // Library Trends. 55:1 (2006) 65-82.

Budd, John; Raber, Douglas (1996). Discourse analysis: method and application in the study of information. // Information Processing \& Management. 32:1 (1996) 217-226.

Carboni, Guilherme (2010). Direito autoral e autoria colaborativa na economia da informação em rede. São Paulo: Quartier Latin, 2010.

Castanha, Renata Cristina Gutierres; Lima, Larissa de Mello; Martínez-Ávila, Daniel (2017). Análise do discurso sob a perspectiva bibliométrica nos estudos de Ciência da Informação no Brasil. // Perspectivas em Ciência da Informação. 22:1 (2017) 17-37.

Escola Nacional de Administração Pública (2015a). Noções gerais de direitos autorais: módulo 1: obras intelectuais. Brasília: [s.n.], 2015. http://repositorio.enap.gov.br/bitstream/handle/1/1852/M\%F3dulo_1_DIREITOS_AUTORAIS.pdf?sequence=1 (2016-01-07).

Escola Nacional de Administração Pública (2015b). Noções gerais de direitos autorais: módulo 2: direitos do autor. Brasília: [s.n.], 2015. http://repositorio.enap.gov.br/ handle/1/1851 (2016-01-07).

España (1996). Real Decreto Legislativo 1/1996, de 12 de abril, por el que se aprueba el texto refundido de la Ley de Propiedad Intelectual, regularizando, aclarando y armonizando las disposiciones legales vigentes sobre la materia. Madrid: Ministerio de Cultura, 1996. https://www.boe.es/buscar/act.php?id=BOE-A-1996-8930 (2017-03-31).

Foucault, Michel. (1984). What is an author? // Rabinow, Paul. (Ed.). The Foucault reader. New York: Pantheon Books, 1984. 101-120.
Frohmann, Bernd (1992). The power of images: a discourse analysis of the cognitive viewpoint. // Journal of Documentation. 48:4 (1992) 365-386.

Frohmann, Bernd (1994a). Discourse analysis as a rese-arch method in library and information science. // Library and Information Science Research. 16:2 (1994) 119-138.

Frohmann, Bernd (1994b). Communication technologies and the politics of postmodern information science. // Canadian Journal of Information and Library Science. 19:2 (1994) 1-22.

Frohmann, Bernd (2001). Discourse and documentation: some implications for pedagogy and research. // Journal of Education for Library \& Information Science. 42:1 (2001) 13-26.

Martínez-Ávila, Daniel (2012). Problems and characteristics of Foucauldian discourse analysis as a research method. // Smiraglia, Richard P.; Lee, Hur-Li. (Eds). Cultural Frames of Knowledge. Ergon: Würzburg, 2012. 99-110.

Martínez-Ávila, Daniel; Fox, Melodie J. (2015). The construction of ontology: a discourse analysis. // Smiraglia, Richard P.; Lee, Hur-Li. (Eds). Ontology for Knowledge Organization. Ergon: Würzburg, 2015. 13-37.

Martínez-Ávila, Daniel; Smiraglia, Richard P.; Lee, Hur-Li; Fox, Melodie (2015). What is an author now? Discourse analysis applied to the idea of an author. // Journal of Documentation. 71:5 (2015) 1094-1114.

Moraes, João Batista Ernesto; Lima, Larissa Mello; Caprioli, Mariana Silva (2016). Análise do discurso e ciência da informação: aportes teóricos para organização e representação da Informação. // Scire. 22:2 (jul.-dic. 2016) 75-85.

Moulaison, Heather Lea; Dykas, Felicity; Budd, John M. (2014). Foucault, the author, and intellectual debt: capturing the author-function through attributes, relationships, and events in knowledge organization systems. // Knowledge Organization 41:1 (2014) 30-43.

O'Farrell, Clare (2007). Key concepts: author. http://www.mi chel-foucault.com/concepts/index.html (2016-07-21).

Olsson, Michael R. (2010). Michel Foucault: discourse, power/knowledge, and the battle for truth. // Leckie, Gloria J.; Given, Lisa M.; Buschman, John. E. (Eds.). Critical theory for Library and Information Science: exploring the social from across the discipline. Santa Barbara: Libraries Unlimited, 2010. 63-74.

Saldanha, Gustavo S.; Gracioso, Luciana S. (2014). Filosofia da linguagem e Ciência da Informação na América Latina: apontamentos sobre pragmática e linguagem. // Rendón Rojas, Miguel Ángel (Org.). El Problema del lenguaje en la Bibliotecología/Ciência de la Información/Documentación: un acercamiento filosófico-teórico. [S.I.]: UNAM. 1-33.

Silva, Rafaela Carolina da; Lima, Larissa de Mello; Suenaga, Cynthia Maria Kiyonaga; Martínez-Ávila, Daniel; Moraes, João Batista Ernesto. Hybrid libraries: a dis-course analysis of the Central Library at Liverpool. // Ibersid. 11:1. (2017).

Smiraglia, Richard P.; Lee, Hur-Li (2012). Rethinking the authorship principle. // Library Trends. 61:1 (2012) 35-48.

Smiraglia, Richard P.; Lee, Hur-Li; Olson, Hope A. (2011). Epistemic presumptions of authorship. // iConference 2011, Inspiration, Integrity, and Intrepidity, ACM, New York, February 8-11. New York: ACM, 2011. 137-143.

Wittgenstein, Ludwig (2009). Investigações filosóficas. 6. ed. Petrópolis: Vozes, 2009.

Enviado: 2017-04-01. Segunda versión: 2017-05-25. Aceptado: 2017-09-14. 